\title{
Ruptured Sub-Annular Mitral Aneurysm in the Pericardium: Report of a Case
}

\author{
Elhadj Yaya Baldé1, Mamadou Bassirou Bah¹, Amadou Djouldé Doumbouya1, \\ Aissatou Tiguidanké Baldé1, Mamadou Cellou Guissé1, Ibrahima Sory Barry ${ }^{1}$, Alpha Konée, \\ Mariam Béavogui ${ }^{1}$, Souleymane Diakité1, Ibrahima Sory 2 Sylla1, Mamadou Aliou Baldé1, \\ Abdoulaye Camara', Mamadou Diallo', Thierno Siradjo Baldé1, Mamadou Dadhi Baldé1, \\ Mamady Condé ${ }^{1}$
}

${ }^{1}$ Cardiology Department of the Ignace Deen Hospital, Conakry, Guinea

${ }^{2}$ Cardiology Department of Donka Hospital, Conakry, Guinea

Email: yaya017balde@gmail.com

How to cite this paper: Baldé, E.Y., Bah, M.B., Doumbouya, A.D., Baldé, A.T., Guissé, M.C., Barry, I.S., Koné, A., Béavogui, M., Diakité, S., 2 Sylla, I.S., Baldé, M.A., Camara, A., Diallo, M., Baldé, T.S., Baldé, M.D. and Condé, M. (2021) Ruptured Sub-Annular Mitral Aneurysm in the Pericardium: Report of a Case. World Journal of Cardiovascular Diseases, 11, 458-463. https://doi.org/10.4236/wjcd.2021.119043

Received: July 29, 2021

Accepted: September 25, 2021

Published: September 28, 2021

Copyright $\odot 2021$ by author(s) and Scientific Research Publishing Inc. This work is licensed under the Creative Commons Attribution International License (CC BY 4.0).

http://creativecommons.org/licenses/by/4.0/

\begin{abstract}
The sub-mitral annular aneurysm is a rare cardiac pathology. The etiologies are diverse, ranging from the congenital form to the idiopathic form, including the acquired form. The clinical case we report is that of a 27 -year-old young man, with no particular history, admitted with a picture of global heart failure. A cardiac ultrasound diagnosed a ruptured mitral sub-annular aneurysm in the pericardium. The difficulty lies in the surgical management of this condition, due to the lack of an adequate cardiac surgery service in most of the countries in Africa south of the Sahara.
\end{abstract}

\section{Keywords}

Sub-Annular Aneurysm, Mitral Valve, Intrapericardial Rupture

\section{Introduction}

Mitral subannular aneurysm is a rare heart disease that can have many different forms and clinical presentations [1]. It was first described in 1962 in Nigeria on autopsy of 7 patients [2]. It has subsequently been described in other sub-Saharan African countries and also in other parts of the world including India [3], South Africa [4] and Senegal [1].

The basic pathology of these lesions has been described as a disjunction between the musculature of the left ventricle, the left atrial region and the mitral valve due to the complex disruption of embryogenesis [5]. In a recent study, Nayak et al. described that the submitral membranous curtain of the mitral valve seen in 45 of 75 open hearts is a potentially weak area, through which true con- 
genital submitral aneurysms can occur [5].

The diagnostic means are transthoracic and transesophageal echocardiography, but also CT scan and magnetic resonance imaging [1] [2] [4] [5] [6] [7]. In this study, we report the case of a ruptured mitral sub-annular aneurysm in the pericardium, diagnosed in the cardiology department of the Ignace Deen National Hospital (Conakry).

\section{Observation}

The patient was a 27-year-old man with no known cardiovascular history who was seen for chest pain and NYHA class III dyspnea. The patient had presented 5 months earlier with an infectious syndrome of undetermined cause. The clinical examination revealed a preserved general condition. The hemodynamic state was stable: the blood pressure was $100 / 60 \mathrm{mmHg}$, oxygen saturation (room air) was $99 \%$. On cardiac auscultation, the heart sounds were regular, muffled, with a heart rate of 87 beats/minute with a systolic breath, intensity $3 / 6$, without radiation. There was no pericardial friction. The vesicular murmur was decreased at both lung bases. The rest of the clinical examination was normal except for a Hackett's stage 3 splenomegaly.

The ECG showed a regular sinus rhythm of 87 beats/minute with left ventricular hypertrophy (Sokolow index Sv1 $+\mathrm{Rv} 5=65 \mathrm{~mm}$ ) and a secondary repolarisation disorder (negative $\mathrm{T}$ waves in the left precordial region, inferior without necrosis Q wave) (Figure 1).

The frontal chest radiograph showed cardiomegaly (ICT $=0.59$ ), at the expense of the left ventricle (Figure 2). Cardiac Doppler ultrasound (Figure 3)

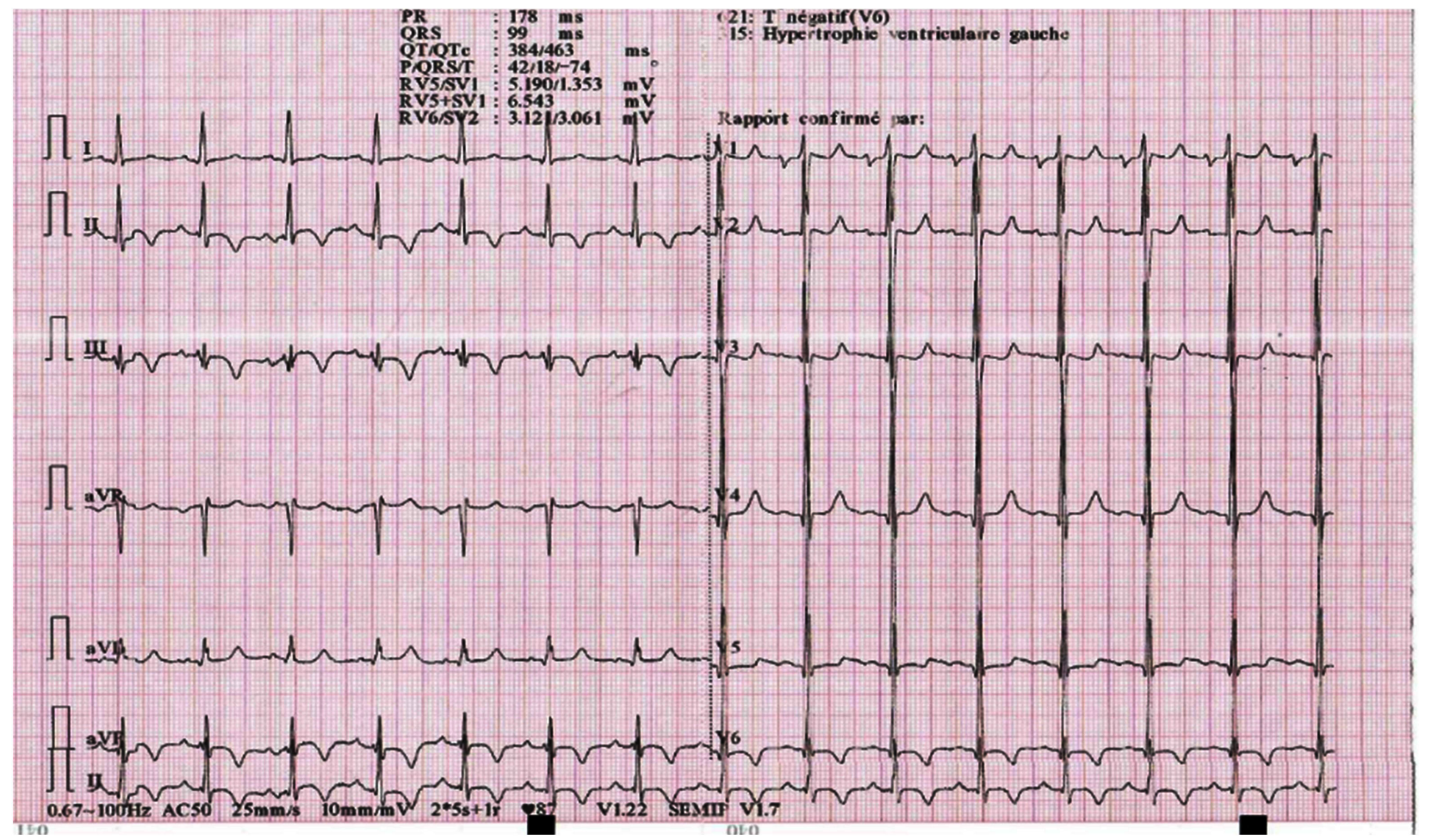

Figure 1. 12-Lead electrocardiogram showing left ventricular hypertrophy and negative T waves in II, III, aVF and V6. 


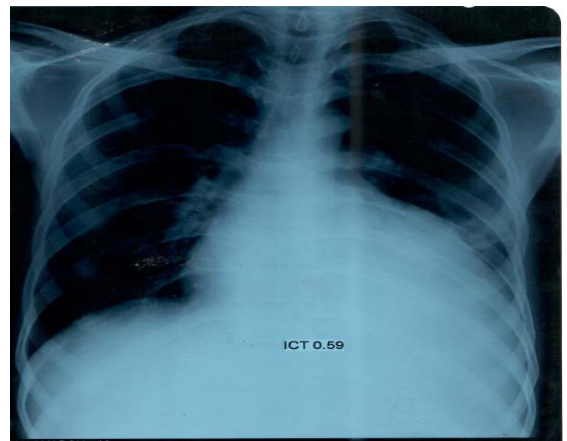

Figure 2. Chest X-ray showing cardiomegaly with a TIA of 0.59 at the expense of the LV. There is no evidence of pulmonary venous hypertension.

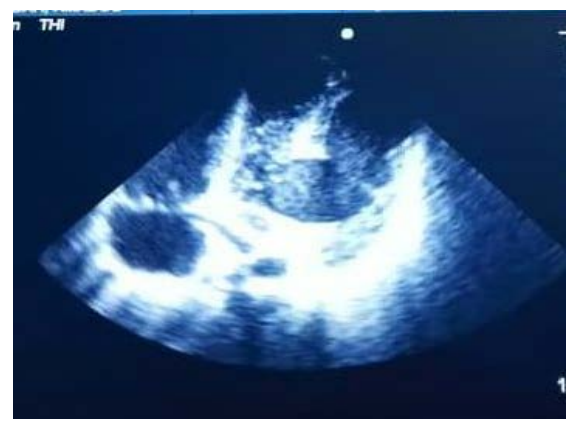

(a)

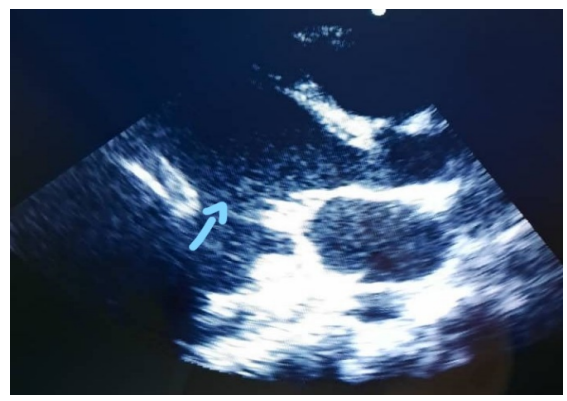

(b)

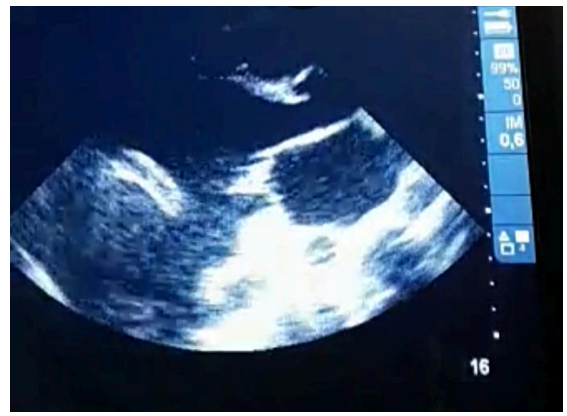

(c)

Figure 3. Ruptured sub-mitral annular aneurysm in the pericardium. (a) Two-dimensional transthoracic echocardiography, apical 4-chamber slice; (b) AND; (c) Two-dimensional transthoracic echocardiography, long-axis parasternal incidence. 
showed moderate dilatation of the left heart chambers. LV: telediastolic diameter $=61 \mathrm{~mm}$; OG: diameter (anteroposterior $=44 \mathrm{~mm}$, OG surface $=29 \mathrm{~cm}^{2}$ ); volume $=33 \mathrm{ml} / \mathrm{m}^{2}$. LV systolic function was preserved ( $\mathrm{EF}=55 \%$ Simpson biplane). There was a grade 1 mitral leak ( $\left.\mathrm{SOR}=12 \mathrm{~mm}^{2}, \mathrm{RV}=13 \mathrm{ml}\right)$ due to annulus dilatation. There was a ruptured mitral sub-annular aneurysm in the pericardium with spontaneous contrast, without signs of compression. The right ventricle had good function. Tricuspid leakage was moderate with a pulmonary arterial pressure of $56 \mathrm{mmHg}$ (DO pressure was estimated at $10 \mathrm{mmHg}$ ).

The biology showed a CRP of $38.40 \mathrm{mg} / \mathrm{l}$, without hyperleukocytosis. The haemoglobin was $11.8 \mathrm{~g} / \mathrm{dl}$.

The evolution was marked by the regression of the signs of cardiac failure after having benefited from a treatment based on a beta-blocker (bisoprolol 1.25 $\mathrm{mg}$ per day), a diuretic (furosemide $40 \mathrm{mg}$ per day) and a conversion enzyme inhibitor (perindopril $5 \mathrm{mg}$ per day).

The patient remained haemodynamically stable for 2 to 3 weeks on this treatment before being evacuated abroad where he underwent heart surgery. The post-operative effects are good and since his return to Guinea, we have been monitoring him. He is doing very well.

\section{Discussion}

Submitral annular aneurysm of the left ventricle is a characteristic anatomical lesion, recognised at autopsy or diagnosed clinically in the absence of coronary thrombosis [2]. Its true incidence is certainly underestimated, especially in the early stages when there are no clinical symptoms [8]. It is mostly seen in young people, particularly Africans living in the tropics [9]. Although a genetic cause has been suggested due to racial predilection, cases have been described in patients of other races from different parts of the world, including India [3]. The role of infection and inflammation in the pathogenesis of this disease including Takayasu's disease [10], tuberculous pericarditis [11], chlamydia pneumoniae infection [9] [12], rheumatic fever [13] among others have been reported. On the other hand, cases of non-infectious and non-traumatic aneurysms support the idea that aneurysms result from a congenital defect of the mitral valve annulus [3] [14]. Patients with annular aneurysms may be asymptomatic or have mitral insufficiency with or without left ventricular dysfunction. They may also present with myocardial ischaemia secondary to left coronary artery compression [15], heart failure, palpitations and lower limb oedema [16], or be found on assessment of a systolic murmur or cardiomegaly [6]. Ventricular arrhythmias (ventricular tachycardia) were another form of presentation of the disease as reported by Rao $\mathrm{M}$ et al. [17]. In our patient, the mode of presentation was the occurrence of chest pain associated with signs of heart failure.

The diagnosis of annular aneurysm was made by transthoracic echocardiography (TTE) showing the rupture (localized dilatation of the posterior wall) communicating the left ventricular cavity, below the posterior mitral leaflet, with 
the pericardium. Doppler examination showed a grade 1 mitral leak. TTE also allows assessment of left ventricular function, the presence or absence of wall thrombus or pericardial effusion, and the status of other valves and pulmonary arterial pressure [18]. Transesophageal echocardiography is used to confirm the diagnosis and to better define the lesions [1] [18]. Several authors have not used CT or MRI scans [1] [4] [9] [15] as they are not essential for diagnosis. However, they are used to further explore the findings of TTE [19], provide information about the coronary arteries and thus avoid the need for coronary angiography as in the study by J Skularigis et al. [15]. Management involves initial medical stabilisation with diuretics and afterload reducing agents.

Open heart surgery is the gold standard in the treatment of sub-annular mitral aneurysm. Two techniques are commonly used: an extracardiac technique to treat the aneurysm via the epicardial route, i.e. under the wall of the aneurysm, and the intrapericardial route described by Antunes, which consists of crossing the atrioventricular groove through the left atrium [8]. Our patient benefited from the latter technique.

The evolution in the absence of surgery is most often marked by a rupture in a cardiac cavity or in the pericardium [1] like this clinical case.

\section{Conclusion}

Sub-annular mitral aneurysm is a rare cardiac condition of varying etiology and clinical presentation. In most cases, echocardiography allows a reliable and precise diagnosis. Treatment is surgical and should be done before rupture, which worsens the prognosis.

\section{Conflicts of Interest}

The authors declare no conflicts of interest regarding the publication of this paper.

\section{References}

[1] Diop, I.B., Leye, M., Diallo, A.D., Sarr, E.H.M., Manga, S.J., Diene, L.L., et al. (2016) Intrapericardial Rupture of a Mitral Subannular Aneurysm: A Case Report and Review of the Literature. Annales de Cardiologie et d Angéiologie (Paris), 65, 99-102. https://doi.org/10.1016/j.ancard.2015.01.013

[2] Cockshott, W.P. (1969) Annular Subvalvular Left Ventricular Aneurysms. Seminars in Roentgenology, 4, 354-359. https://doi.org/10.1016/0037-198X(69)90025-X

[3] Baruah, D.K., Naresh Kumar, P.V., Reddy, G.S. and Ramesh Babu, V. (2012) Submitral Aneurysm of the Left Ventricle. Indian Heart Journal, 64, 77-79. https://doi.org/10.1016/S0019-4832(12)60015-7

[4] Chesler, E., Joffe, N., Schamroth, L. and Meyers, A. (1965) Annular Subvalvular Left Ventricular Aneurysms in the South African Bantu. Circulation, 32, 43-51. https://doi.org/10.1161/01.CIR.32.1.43

[5] Nayak, V.M. and Victor, S. (2006) Sub-Mitral Membranous Curtain: A Potential Anatomical Basis for Congenital Sub-Mitral Aneurysms. Indian Journal of Thoracic and Cardiovascular Surgery, 22, 205-211. 
https://doi.org/10.1007/s12055-006-0003-4

[6] Bouramoue, C., Nkoua, J.L., Gombet, T., Kimbally-Kaky, G. and Ekoba, J. (1995) Anévrismes sous-annulaires idiopathiques du ventricule gauche: Caractères anatomiques, cliniques et évolutifs: À propos de 13 cas. Annales de Cardiologie et d'Angéiologie, 44, 7-13.

[7] Chen, C.C., Hsiung, M.C., Wei, J., Chang, W.T., Yin, W.H. and Young, M.S. (2005) Mitral Annular Subvalvular Left Ventricular Aneurysm. Echocardiography, 22, 434-437. https://doi.org/10.1111/j.1540-8175.2005.04016.x

[8] Du Toit, H.J., Von Oppell, U.O., Hewitson, J., Lawrenson, J. and Davies, J. (2003) Left Ventricular Sub-Valvar Mitral Aneurysms. Interactive CardioVascular and Thoracic Surgery, 2, 547-551. https://doi.org/10.1016/S1569-9293(03)00141-5

[9] Cenac, A., Chaigneau, C., Sueur, J.M. and Orfila, J. (2002) Anevrisme annulaire sous-mitral, cardiomyopathie postpartum et anticorps anti-Chlamydia pneumoniae a Niamey (Niger). Medicina Tropical, 62, 81-84.

[10] Rose, A.G. (1997) Ruptured Idiopathic Left Ventricular False Aneurysm of the Free Wall Associated with Takayasu's Arteritis in a Young Child. South African Medical Journal, 87, C161-C164.

[11] Lintermans, J.P. (1976) Calcified Subvalvular Left Ventricular Aneurysm: An Unusual Case in a 4-Year-Old Child. Pediatric Radiology, 4, 193-196.

https://doi.org/10.1007/BF00975357

[12] Bachmaier, K., Nikolaus, N., De La Maza, L.M., Sukumar, P., Hessel, A. and Penninger, J.M. (1999) Chlamydia Infections and Heart Disease Linked through Antigenic Mimicry. Science, 283, 1335-1339. https://doi.org/10.1126/science.283.5406.1335

[13] Hirachan, A., Hirachan, G.P. and Kc, B. (2018) A Case of Large Sub Mitral Aneurysm with Rheumatic Heart Disease. Nepalese Heart Journal, 15, 39-40.

https://doi.org/10.3126/njh.v15i2.21476

[14] Chesler, E., Mitha, A.S. and Edwards, J.E. (1982) Congenital Aneurysms Adjacent to the Anuli of the Aortic and/or Mitral Valves. Chest, 82, 334-337. https://doi.org/10.1378/chest.82.3.334

[15] Skularigis, P.S. (1997) Anévrisme ventriculaire gauche de soumission comprimant l'artère coronaire principale gauche. Catheterization and Cardiovascular Diagnosis, 40, 173-175.

[16] Lee, C.H., Lee, D.K. and Lim, S.H. (2016) Anesthetic Management during Surgery for Left Ventricular Aneurysm and False Aneurysm Occurring in Stage: A Case Report. Korean Journal of Anesthesiology, 69, 518-522. https://doi.org/10.4097/kjae.2016.69.5.518

[17] Rao, M., Panduranga, P. and Mukhaini, M. (2010) Ventricular Tachycardia Secondary to a Submitral Left Ventricular Aneurysm Diagnosed in Emergency Department-A Case Report from Oman. International Journal of Emergency Medicine, 3, 499-500. https://doi.org/10.1007/s12245-010-0203-y

[18] Jahangiri, M., Sarkar, D., Quinton, P. and Ward, D.E. (2005) Submitral Left Ventricular Pseudoaneurysm. The Annals of Thoracic Surgery, 79, 1031-1032. https://doi.org/10.1016/j.athoracsur.2003.09.134

[19] Sanagar, S., Kaushik, S., Jadhav, S., Tiwari, S. and Gupta, R. (2020) Transaneurysmal Repair of a Giant Calcified Submitral Left Ventricular Aneurysm. Brazilian Journal of Cardiovascular Surgery, 35, 844-846. https://doi.org/10.21470/1678-9741-2019-0113 